\title{
Study of Mechanical Behavior and X-Ray Elastic Constants of Nickel Alloy Weld Overlay
}

\author{
Vladimir Ivanovitch Monine ${ }^{a}$, Rodrigo Stohler Gonzaga ${ }^{a}{ }^{\mathbb{D}}$, Francisco Werley Cipriano Farias ${ }^{a}$, \\ Elisa Kimus Dias Passos ${ }^{a}$, João da Cruz Payão Filho ${ }^{a}$ \\ aPrograma de Engenharia Metalúrgica e de Materiais, Instituto Alberto Luiz Coimbra de Pós-Graduação \\ e Pesquisa de Engenharia, Universidade Federal do Rio de Janeiro, Av. Horácio Macedo, 2030, Cidade \\ Universitária, 21941-972, Rio de Janeiro, RJ, Brasil
}

Received: November 08, 2018; Revised: May 07, 2019; Accepted: May 20, 2019

The study of nickel-based alloy 625 clad (weld overlay) by X-ray diffraction (XRD) is difficult and often impossible because of its coarse and anisotropic microstructure. In this work, a sample preparation including machining, grinding, and annealing was proposed to avoid this negative effect in XRD analysis. Electron backscatter diffraction and hardness testing were used to evaluate the microstructure of the surface and the inner region of a sample during its preparation. The proposed sample preparation allowed accurate determination of the Young's modulus and the Poisson ratio through XRD. The values obtained using a small bending fixture are $212 \pm 2 \mathrm{GPa}$ and $0.31 \pm 0.01$, respectively.

Keywords: Nickel alloy weld overlay, EBSD analysis, Vickers hardness, X-ray elastic constants.

\section{Introduction}

In the oil and gas industry, where the equipment for fossil fuel processing must present good mechanical properties and high corrosion resistance, cladded components provide an excellent combination of these properties with lower cost in relation to nickel alloy monolithic components ${ }^{1,2}$. One of the processes largely employed to manufacture cladded components is arc welding, owing to its low cost, high quality, and capability to overlay complex geometries. Clad is characterized by local inhomogeneous heating and cooling that generate residual stresses in a part ${ }^{3,4}$. The influence of residual stress on fatigue, corrosion resistance and stress corrosion cracking ${ }^{5-9}$ is crucial toward understanding the importance of the residual stress state analysis in cladded components.

The stress state analysis of materials through the $\mathrm{X}$-ray diffraction (XRD) method is widely used in various technological areas owing to its accuracy and precision ${ }^{10,11}$. However, application of the XRD technique to materials with coarse-grained and preferentially oriented microstructure, such as nickel alloy clad, is quite complex and requires a thoughtful approach to the experimental procedure.

The coarse-grained microstructure and crystallographic anisotropy of nickel alloy clad affect the accuracy of XRD stress analysis. It should be noted that the discrete character of powder reflections caused by a coarse-grained microstructure could be improved by sample oscillation during the measurement. However, the strong anisotropy accompanying the coarse-grained microstructure leads to diffraction in some restricted grains, which makes it impossible to perform traditional XRD stress measurements in metals with this type of microstructure.
The problem in determining the elastic constants using XRD stress analysis is that their values are different from those measured by mechanical methods. This difference is associated with the selective characteristic of crystalline planes involved in diffraction phenomena. This selectivity of $\mathrm{X}$-ray diffraction leads to dependency by the elastic constant magnitudes on the orientation of the lattice planes specified by Miller Indices. Theoretical calculation of XRD elastic constants based on the Voight and Reuss assumptions ${ }^{12,13}$ is simple and well-suited for pure metals, but the calculation is difficult for X-ray elastic constants involving high alloyed metals, such as a nickel-based alloys solid solution strengthened with chromium, molybdenum, and niobium.

In this work, a sample preparation process is proposed to avoid the negative effects of the coarse grain and microstructure anisotropy of a nickel-based alloy 625 clad on X-ray diffraction analysis. Electron backscatter diffraction (EBSD) and Vickers hardness were used to evaluate the microstructure change of the clad during machining and heat treatment. A portable bending fixture was used for determination of the X-ray elastic constants and the study of stress-strain relationships of thin samples extracted from a nickel alloy-clad pipe.

\section{Materials and Methods}

\subsection{Materials}

A 9\% nickel (Ni) steel seamless thick-walled pipe was gas tungsten arc (GTA) cladded with two layers of Ni-based alloy 625 (AWS ER NiCrMo-3). The final clad thickness is $4.5 \mathrm{~mm}$. The chemical compositions of the $9 \% \mathrm{Ni}$ steel pipe, 
the nickel alloy filler metal, and the clad layers obtained by optical emission spectroscopy are presented in Table 1 . The welding parameters are listed in Table 2. The test pieces for study were cut from the cladded pipe and milled as shown in Figure 1.

After milling and grinding (Figure 1b), the sample was removed from the second layer by electron discharge machining (EDM). The sample (140 mm x $15 \mathrm{~mm}$ x $1 \mathrm{~mm}$ ) shown in Figure 1c was then encapsulated and sealed in a quartz tube and annealed for $1 \mathrm{~h}$ at $1000^{\circ} \mathrm{C}$. The oxide film formed on the sample surface during annealing was removed by pickling in $2 \%$ HF aqueous solution. The experimental choice of the annealing conditions was based on the need to eliminate the residual stresses introduced in the surface layer by milling and grinding, balanced by the need to avoid any significant microstructure change. The XRD confirmed that the annealed clad does not present surface residual stress.

Table 1. Specified and analyzed chemical compositions of Ni-based superalloy 625, filler metal and clad layers obtained by optical emission spectroscopy

\begin{tabular}{|c|c|c|c|c|c|}
\hline \multirow{4}{*}{ Chemical element } & \multicolumn{5}{|c|}{ Chemical composition (weight \%) } \\
\hline & \multicolumn{2}{|c|}{ Substrate } & \multirow{3}{*}{$\begin{array}{c}\text { Filler metal } \\
\text { Specified [15], max. }\end{array}$} & \multicolumn{2}{|c|}{ Clad } \\
\hline & \multirow{2}{*}{ Specified [14], max. } & \multirow{2}{*}{ Analyzed } & & $1^{\text {st }}$ layer & $2^{\text {nd }}$ layer \\
\hline & & & & Analyzed & Analyzed \\
\hline $\mathrm{C}$ & 0.13 & 0.067 & 0.10 & 0.038 & 0.031 \\
\hline $\mathrm{Si}$ & $0.13 / 0.32$ & 0.28 & 0.50 & 0.249 & 0.244 \\
\hline $\mathrm{Mn}$ & 0.90 & 0.61 & 0.50 & 0.326 & 0.26 \\
\hline $\mathrm{P}$ & 0.025 & $<0.005$ & 0.02 & 0.002 & 0.001 \\
\hline S & 0.025 & $<0.005$ & 0.015 & 0.003 & 0.003 \\
\hline $\mathrm{Fe}$ & Bal. & Bal. & 5.0 & 23.7 & 8.56 \\
\hline $\mathrm{Al}$ & N.A. & 0.022 & 0.40 & 0.08 & 0.092 \\
\hline $\mathrm{Ti}$ & N. A. & 0.006 & 0.40 & 0.16 & 0.198 \\
\hline $\mathrm{Ni}$ & $8.4 / 9.6$ & 9.23 & $58.0 \mathrm{~min}$. & 51.9 & 61.6 \\
\hline $\mathrm{Cu}$ & N. A. & $<0.005$ & 0.50 & 0.019 & 0.023 \\
\hline $\mathrm{Cr}$ & N. A. & 0.056 & $20.0-23.0$ & 13.5 & 16.8 \\
\hline $\mathrm{Nb}+\mathrm{Ta}$ & N. A. & $<0.005$ & $3.15-4.15$ & 2.13 & 2.75 \\
\hline Mo & 0.50 & 0.014 & $8.0-10.0$ & 7.43 & 9.09 \\
\hline
\end{tabular}

N. A. means not applicable

Table 2. Process, parameters, and variables adopted to clad the $9 \%$ Ni steel seamless pipe with Ni-based alloy 625 . GTAW-HW means hot wire gas tungsten arc welding

\begin{tabular}{|c|c|c|c|}
\hline \multicolumn{2}{|c|}{ Welding process, parameter, or variable } & $1^{\text {st }}$ layer & $2^{\text {nd }}$ layer \\
\hline \multicolumn{2}{|l|}{ Welding process } & GTAW-HW & GTAW-HW \\
\hline \multirow{2}{*}{ Shielding gas } & Type & Argon & Argon \\
\hline & Flow rate $[1 / \mathrm{min}]$ & 18 & 18 \\
\hline \multirow{2}{*}{ Welding current } & Type & $\mathrm{DC}$ & $\mathrm{DC}$ \\
\hline & Polarity & Direct & Direct \\
\hline \multirow{2}{*}{ Electrode } & Type & EW-La2 & EW-La2 \\
\hline & Diameter $[\mathrm{mm}]$ & 3.2 & 3.2 \\
\hline \multicolumn{2}{|c|}{ Peak current, Ip [A] } & 258.2 & 259.6 \\
\hline \multicolumn{2}{|c|}{ Base current, $\mathrm{Ib}[\mathrm{A}]$} & 177.9 & 176.6 \\
\hline \multicolumn{2}{|l|}{ Voltage, U [V] } & 12.7 & 12.7 \\
\hline \multicolumn{2}{|c|}{ Welding speed, WS [mm/min] } & 300 & 320 \\
\hline \multicolumn{2}{|c|}{ Wire feed speed, WFS [m/min] } & 1.5 & 2.5 \\
\hline \multicolumn{2}{|c|}{ Preheat temperature $\left[{ }^{\circ} \mathrm{C}\right]$} & 80 & 30 \\
\hline \multicolumn{2}{|c|}{ Interpass temperature $\left[{ }^{\circ} \mathrm{C}\right]$} & 93 & 101 \\
\hline \multicolumn{2}{|c|}{ Heat input, $\mathrm{HI}[\mathrm{kJ} / \mathrm{mm}]$} & 0.654 & 0.611 \\
\hline
\end{tabular}




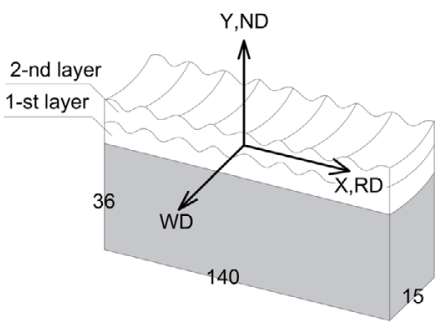

a

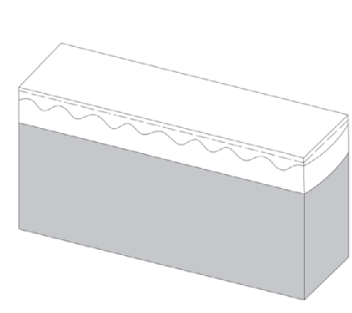

b

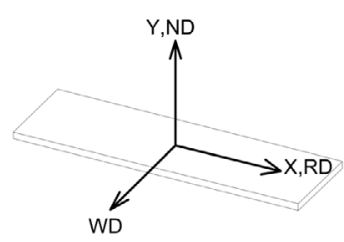

C

Figure 1. Preparation sequence of a sample machined from the Ni-based alloy 625 clad: (a) rectangular sample after cutting, (b) external clad ( $2^{\text {nd }}$ layer) after milling and grinding marked with dashed line for electron discharge cutting, (c) $1 \mathrm{~mm}$ thick sample and corresponding coordinate system. WD, RD, and ND are the welding, pipe rolling, and surface normal directions, respectively. Dimensions are in $\mathrm{mm}$.

\subsection{Microstructural and hardness evaluation}

Electron backscatter diffraction (EBSD) was performed with a FEI Quanta 450 scanning electron microscope (Bruker $e^{-}$Flash model) at $20 \mathrm{kV}$ and a step size between 1.19 $\mu \mathrm{m}$ and $6.56 \mu \mathrm{m}$. The samples were prepared according to standard metallographic techniques with a final automated polishing using $0.04 \mu \mathrm{m}$ colloidal silica solution for $1 \mathrm{~h}$. In this work, EBSD was used for microstructural evaluation of aswelded and annealed clad samples. For a pair of samples in the as-welded and in the annealed conditions, the analyzed regions were perpendicular to the welding direction(WD), as shown in Figure 1c. The regions of the annealed clad samples analyzed were parallel to the $\mathrm{WD}$, and among these samples, one was submitted to electrochemical polishing to remove a thin $(0.15$ $\mathrm{mm}$ ) machined and annealed surface layer. Post-processing of the EBSD data was carried out with the MTEX-Free and Open Source Software Toolbox extension ${ }^{16}$.

When the metal is plastically strained, there is an increase in the dislocation density, composed of geometrically necessary dislocations (GND) and statistically stored dislocations ${ }^{17}$. The GNDs are the result of a strain gradient and are directly related to the orientations measured in the EBSD. The misorientation between adjacent points can be represented by the kernel average misorientation (KAM). Therefore, the intragranular misorientation is directly related to the GND density, which depends on the geometry of the grain boundaries, the average spacing of all dislocation boundaries, and the Burgers vector ${ }^{18}$. Thus, the KAM peak for a large range of misorientation angles is related to high dislocation density. In this work, a threshold angle of $5^{\circ}$ was used for KAM measurement, where higher misorientation angles were considered as low angle grain. The step sizes used for the second layer of the as-welded and annealed clad were $6.56 \mu \mathrm{m}$ and $1.19 \mu \mathrm{m}$, respectively.

Grain boundary character distribution (GBCD) was assessed owing to its high influence on the material properties. In this study, misorientation angles less than $5^{\circ}$ were considered to characterize a subgrain or low angle boundary, while medium and high angle boundaries were those with misorientation angles between $5^{\circ}$ and $10^{\circ}$, and above $10^{\circ}$, respectively.

Vickers hardness was performed according to ASTM E384$17^{19}$ and ASTM E92- $17^{20}$ with different loads $(4.9 \mathrm{~N}, 9.8 \mathrm{~N}, 49$ $\mathrm{N}$, and $98 \mathrm{~N}$ ) and dwell time of $20 \mathrm{~s}$ to evaluate microstructural changes in the nickel-based alloy 625 clad during the heat treatment. Standardized hardness test blocks were used to calibrate the hardness test machine ${ }^{20}$.

\subsection{X-ray diffraction}

The X-ray elastic constants were determined using a mini diffractometer with chromium anode X-ray tube. The equipment used for XRD experiments (Figure 2) included a position sensitive detector and a special collimator with two slits that can smoothly change the incident X-ray beam width from $0.1 \mathrm{~mm}$ to $2 \mathrm{~mm}$ and its height from $0.1 \mathrm{~mm}$ to $8 \mathrm{~mm}$. An oscillating base that provided more accurate and precise acquired data with reduced X-ray exposure time was also included. Calibration and adjustment of the X-ray equipment were performed using fine electrolytic tungsten powder. Periodical exposures to this powder were carried out to control the repeatability and reproducibility of the experimental data obtained by the X-ray system.

\subsection{Young's modulus determination}

The stress-strain relationship of the metal under pure bending can be determined by the bending moment and the deflection of a bent sample (Figure 3a). The bending fixture schematic is illustrated in Figure $3 \mathrm{~b}$.

Based on Figure $3 \mathrm{~b}$, the bending moment caused by the fixture spring can be expressed as:

$$
M_{b}=F H \cos \beta
$$

Here, $F$ is the force induced by the spring, $H$ is the lever arm length, and $\beta$ is the sample support inclination (equal to $\left.\beta=\cos ^{-1}\left(\left(\mathrm{~L}_{\text {upp }}-\mathrm{L}_{\text {low }}\right) / 2 \mathrm{H}\right)\right)$. The lever arm length $H$ must be increased by an amount equal to the total deflection $\delta_{\text {total }}$ of the 


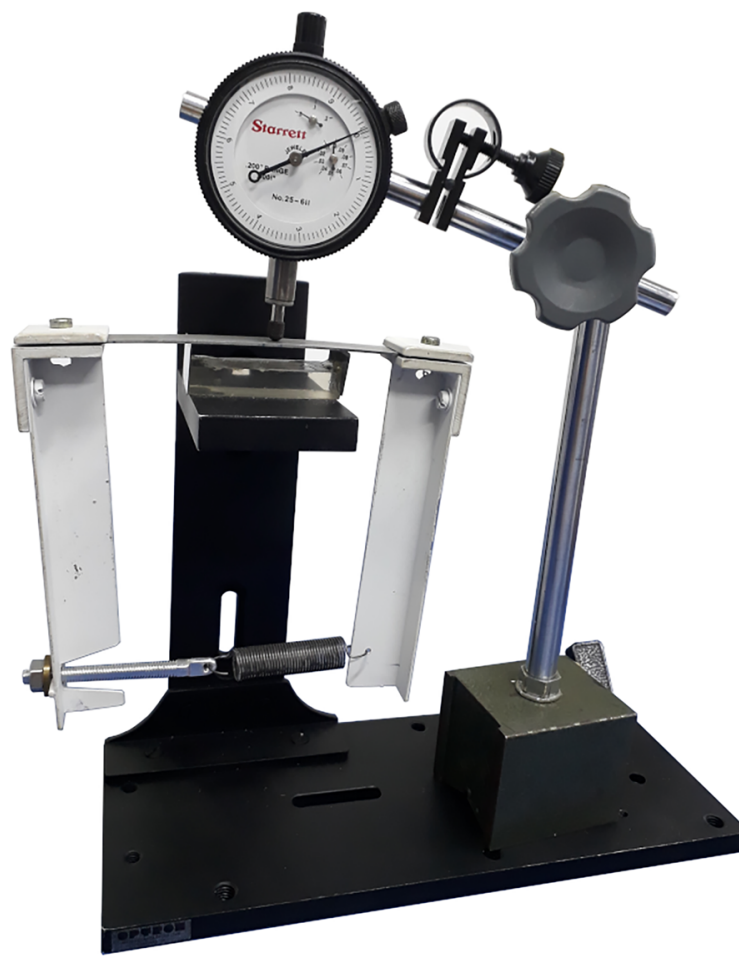

a

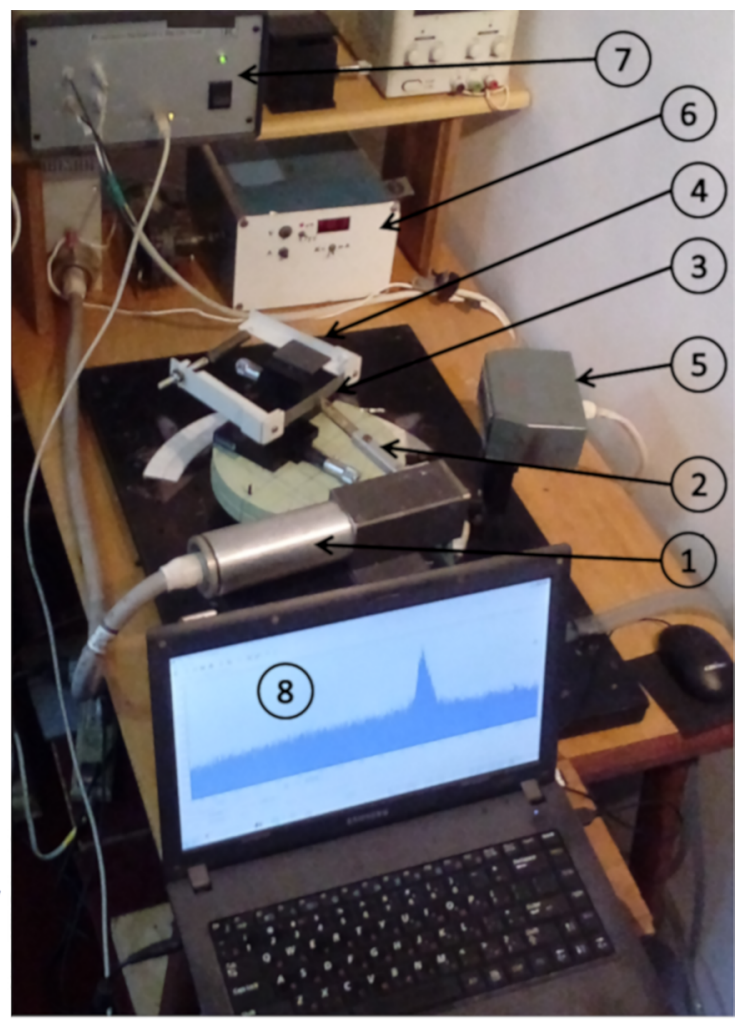

b

Figure 2. Experimental setups: (a) bend testing of flat nickel-based alloy 625 clad sample; and (b) apparatus for elastic constants measurements: (1) X-ray tube, (2) collimator, (3) nickel-based alloy 625 clad sample, (4) fixture with loading spring, (5) PSD detector, (6) high voltage source, (7) detector control unit, (8) PC monitor showing (220) diffraction line of analyzed sample.

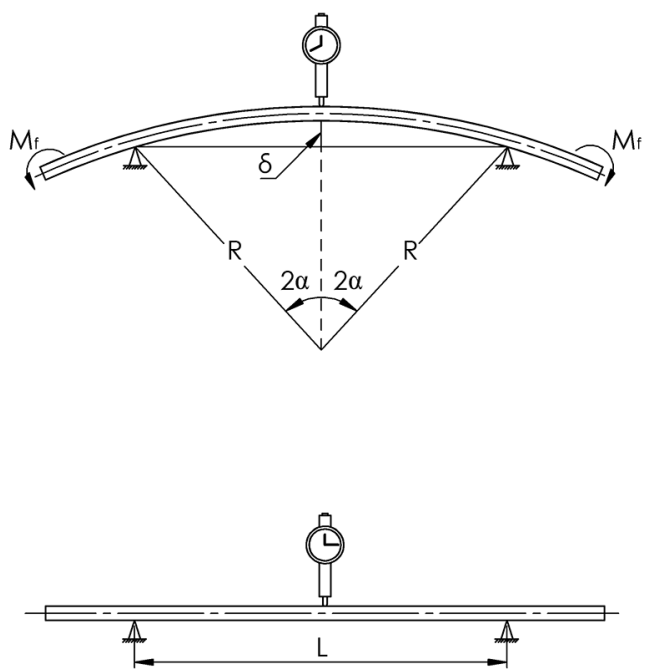

a

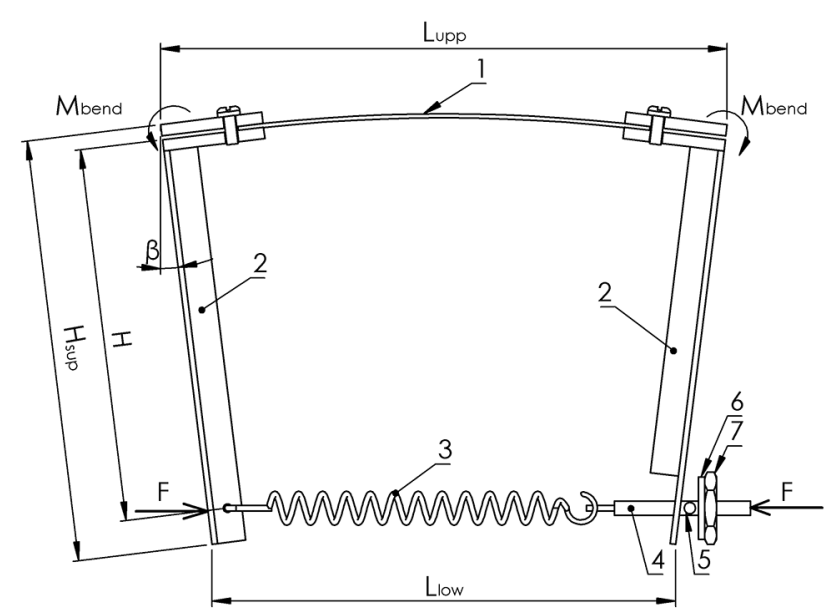

b

Figure 3. Deflection measurements of bending sample with (a) rectangular cross section; (b) the fixture for pure bending loading: (1) sample, (2) support beams, (3) loading spring, (4) screw, (5) pin, (6) washer, (7) nut. 
bent sample. Therefore, the corrected magnitude of the lever $\operatorname{arm} H_{\text {corr }}$ shown in Figure $3 \mathrm{~b}$ is:

$$
H_{\text {corr }}=H \cos (\beta)+\delta_{\text {total }}
$$

Finally, the tensile normal stress on the convex surface of the bent sample is:

$$
\sigma=\frac{6 M_{b}}{b h^{2}}
$$

Here, $M_{b}$ is the bending moment expressed by Equations (1) and (2), and $b$ and $h$ are the width and thickness of the rectangular sample, respectively. Then, the final equation for the normal stress on the sample surface is:

$$
\sigma=\frac{6 k \Delta l H_{\text {corr }}}{b h^{2}}
$$

Here, $\Delta \mathrm{l}$ is the spring elongation and $k$ is the spring stiffness constant $(k=0.086 \mathrm{~N} / \mathrm{mm})$.

The normal strain in the surface layer can be determined using the sample's deflection $\delta$ (Figure 3a). For the determination of the bent sample's neutral line deflection, a correction would normally be necessary, but as the bending radius magnitude is much larger than the sample thickness, the difference between the measured and corrected deflections is negligible. The applied stresses for loading the nickel-based alloy 625 samples were between $80 \mathrm{MPa}$ and $200 \mathrm{MPa}$.

According to bending theory, the strain in the surface layer is expressed as:

$$
\varepsilon=\frac{h}{2 R_{n}}
$$

Here, the radius of the neutral line circle $R_{n}$ is equal to $(\mathrm{R}+0.5 h)$. Omitting the details of the geometric relationships between deflection $\delta$, the bent sample radius $\mathrm{R}$, and half of the angle between the deflection points (Figure 3a), R can be expressed as:

$$
R=\frac{L}{2 \sin (2 \alpha)}
$$

where

$$
2 \alpha=2 \tan ^{-1}\left(\frac{2 \delta}{L}\right)
$$

Finally, the surface normal strain of the bent sample can be determined as:

$$
\varepsilon=\frac{h \sin (2 \alpha)}{L+h \sin (2 \alpha)}
$$

Hence, a variation of the spring elongation $(\Delta \mathrm{l})$ changes the normal stress magnitudes on the sample surface layer expressed by Equation (4). In the same manner, the normal strains expressed by Equation (8) are calculated for the corresponding deflection values.

\subsection{Determination of the $X$-ray elastic constants}

The X-ray elastic constants were determined with $\mathrm{K}_{\alpha}-\mathrm{Cr}$ radiation using the (220) plane reflections at $\psi$-tilts equal to $0^{\circ}, 24^{\circ}, 35^{\circ}, 46^{\circ}$, and $55^{\circ}$. The calculation of X-ray elastic constants can be found $\mathrm{in}^{21}$. The dependence of the diffraction line position on the $\sin ^{2} \psi$ tilts for different loads on the Ni-based alloy 625 clad provides the data necessary for determination of the X-ray elastic constants.

The diffraction line position was determined after experimental data processing and fitted using the modified Cauchy (or Lorentzian) function expressed as:

$$
y(x)=\frac{1}{\left(1+a(x-b)^{2}\right)^{n}}+\frac{0,5}{\left(1+a(x-b-\delta)^{2}\right)^{n}}
$$

where $a$ and $n$ are parameters related to the width and growth rate of the bell-shaped function, respectively, $\delta$ is the $K_{\alpha}$ interdoublet distance, and $b$ is the $K_{\alpha l}$ diffraction peak (diffraction angle) position. Modification of this function is associated with the use of the exponent $n$, which can be any integer or fractional number. This allows fitting of experimental data to be more accurate and reliable.

The first and second terms on the right side of Equation (9) relate to the $K_{a 1}$ and $K_{a 2}$ components, respectively, with normalized intensities equal to 1 and 0.5 . Figure 4 a shows an example of the fitting function expressed by Equation (9) for the experimental diffraction line of the electrolytic tungsten powder used as the standard sample for calibration and adjustment of the X-ray equipment. The parameter $b$ corresponding to the tungsten (211) $K_{a l}$ diffraction angle position is equal to $124.79^{\circ}$. Figure $4 \mathrm{~b}$ shows the (220) experimental diffraction line for the Ni-based alloy 625 clad after machining and heat treatment (annealing), where the diffraction angle is equal to $128.47^{\circ}$. The size of the scanned area depends on the variation of the psi-angle, where values of $2.4 \mathrm{~mm}^{2}$ (for $\psi=0^{\circ}$ ) and $14 \mathrm{~mm}^{2}$ (for $\psi=55^{\circ}$ ) may be found.

The Young's modulus and Poisson's ratio were determined by XRD using the $\sin ^{2} \psi$-method, where, according to Noyan and $\mathrm{Cohen}^{13}$, the diffraction angle measured at different sample tilts can be expressed as a linear function of $\sin ^{2} \psi$ :

$$
\theta_{\psi}=\theta_{0}-\sigma_{1} \frac{(1+v)}{E} \frac{\sin ^{2} \psi}{\cot \theta_{0}}+\frac{v}{E \cot \theta_{0}} \sigma_{1}
$$

The diffraction angles obtained for $\psi$-tilts equal to $0^{\circ}$ and $90^{\circ}$ can be used for determination of the X-ray Young's modulus and Poisson's ratio. Figure 5 shows an example of the experimental data plots used for determination of the elastic constants by XRD stress measurements.

For fixed applied stress $\sigma_{l}$, the interception of the straight line $\theta_{\psi}=f\left(\sin ^{2} \psi\right)$ with the $\theta_{\psi}$ axis (defined as $\left.\theta_{\psi=0}\right)$ and extrapolated to $\psi$ equal to $90^{\circ}$ magnitude $\left(\theta_{\psi=90}\right)$ allows the base equations for $\mathrm{X}$-ray constants to be obtained as:

$$
\begin{gathered}
\theta_{\psi=0}-\theta_{0}=\frac{v}{E \cot \theta_{0}} \sigma_{1} \\
\theta_{\psi=90}-\theta_{\psi=0}=-\frac{(1+v)}{E \cot \theta_{0}} \sigma_{1}
\end{gathered}
$$

where $\theta_{0}$ is the diffraction angle for unstressed material. The combinations of the Young's modulus and Poisson's 


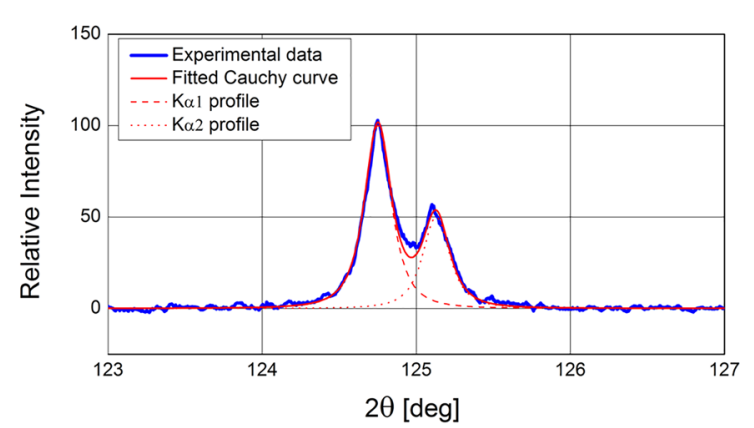

a

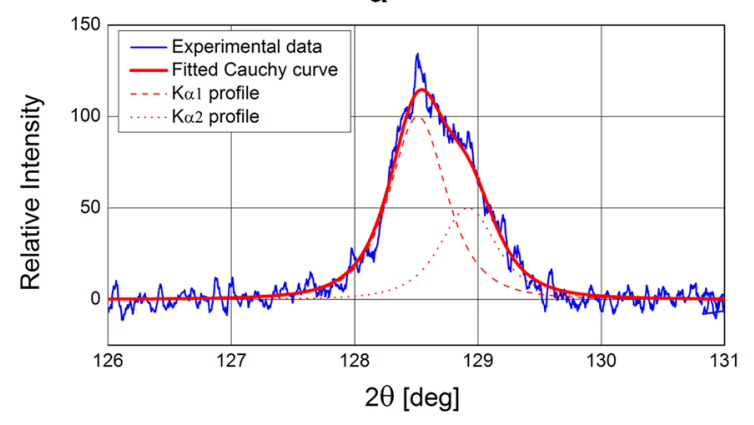

b

Figure 4. Fitting of diffraction profiles: (a) the tungsten (211) diffraction line and (b) the (220) diffraction line of the Ni-based alloy 625 clad after machining and heat treatment (annealing).

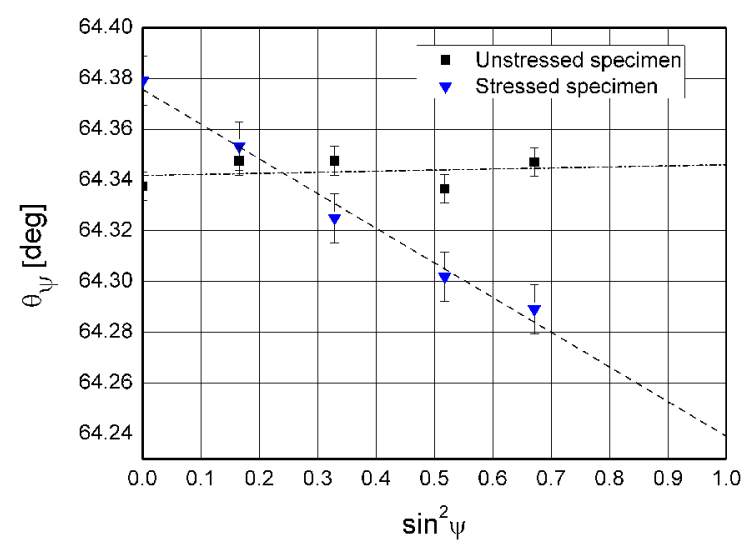

Figure 5. Experimental relationships $\left(\theta_{\psi}=f\left(\sin ^{2} \psi\right)\right)$ used for determination of the $\mathrm{X}$-ray elastic constants: squares and triangles correspond to experimental data and to data processed by linear regression graphs for unstressed and loaded samples $(\sigma=187$ $\mathrm{MPa})$, respectively.

ratio of the material referred to the X-ray elastic constants $S_{1}=\frac{v}{E}$ and $\frac{1}{2} S_{2}=\frac{(1+v)}{E}$ can be determined as the slopes $\tan \left(\alpha_{1}\right)$ and $\tan \left(\alpha_{2}\right)$ of linear functions (11) and (12), respectively. When $\sigma_{1}$ is varied in the range of specified loading stresses, then:

$$
\begin{gathered}
S_{1}=\frac{\tan \alpha_{1}}{\tan \theta_{0}} \\
\frac{1}{2} S_{2}=-\frac{\tan \alpha_{2}}{\tan \theta_{0}}
\end{gathered}
$$

\section{Results and discussion}

\subsection{Hardness and EBSD}

The Vickers microhardness measurements presented in Figure 6 show that there was no significant change in the mechanical behavior of the weld overlay in both conditions, even though metallurgical effects, such as the growth of solidification interdendritic precipitates with reduction of hardening elements content in solid solution, may take place, e.g. carbides and topologically closed packed phases ${ }^{22,23}$. In addition, the load value influences the dispersion of the microhardness measurements, because a decrease in the load magnitude will cause a decrease in the indentation area and, consequently, grain boundaries and hard precipitates may influence the hardness value. Thus, the increase in the microhardness value for load of $9.8 \mathrm{~N}$, observed for the sample machined and annealed, is attributed to the microstructural heterogeneities, such as the presence of several phases with distinct mechanical properties and the variation of grain size found in the weld metal.

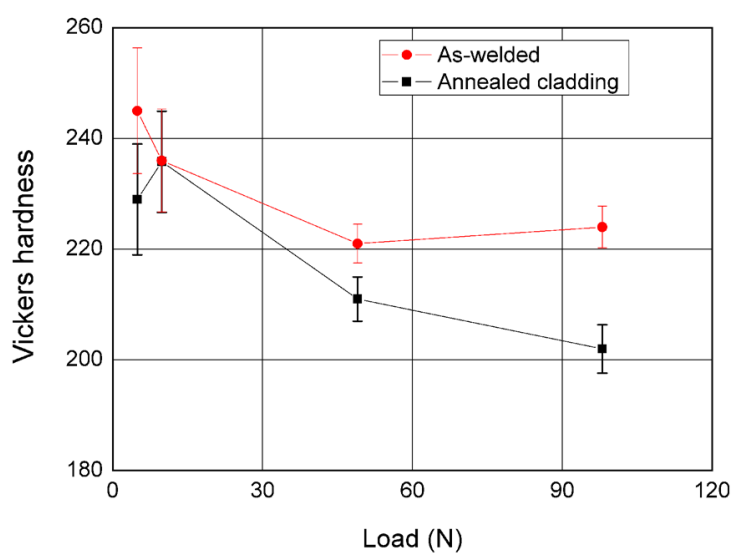

Figure 6. Vickers hardness testing of the as-welded and annealed clad samples.

As it was expected, the "as-welded" sample presented higher hardness values than the "annealed after machining" sample. Cortial and co-workers ${ }^{24}$ shown the larger amount of interdendritic precipitates in the "as-welded" condition and the leaner microstructure of the sample heat treated during $8 \mathrm{~h}$ at $1.000{ }^{\circ} \mathrm{C}$. The general behavior of the specimen's hardness, i.e. the larger loads, presented no significant difference as the hardness values area within approximately $10 \%$ range, which is not unusual in hardness measurements. As the hardness load decreases the hardness value increases because the smaller indentation area for low loads may hit grain boundaries and precipitates. For higher loads, the indentation area is larger and a general estimative of mechanical resistance is obtained ${ }^{25}$. 
Inverse pole figure maps obtained by EBSD for the aswelded and annealed clads are presented in Figures 7 and 8, respectively, where the analyzed surfaces were perpendicular and parallel to the welding direction, respectively. The aswelded microstructure, according to Figure 7.a, is characterized by coarse grains and light texture in the directions [111] and [001] for the central and near surface regions, respectively. As indicated by Kim et al. ${ }^{26}$, the weld pool solidification ends on the surface and some grains in the clad face change their solidification directions because of other more efficient heat extraction sources in the final moments of solidification, creating grains almost parallel to the surface.

The GBCD analysis (Figure 9) shows that the as-welded clad has a higher relative frequency for misorientation angles greater than $10^{\circ}$, especially in the middle of the clad thickness (Figure 7a). In the annealed clad, different behaviors were observed for the regions near and far from the machined surface. In the latter, the relative frequency of misorientation angles below $5^{\circ}$ is very high, characterizing a rearrangement of dislocations and subgrain formation, which driving force originated from the mutual cancellation of the elastic stress fields produced by the dislocations ${ }^{27}$. Therefore, the high temperature during welding in the subsequent pass enables this rearrangement through dislocations movement. In the mechanically polished surface, the misorientation angles presented similar behavior to the as-welded clad, with a higher relative frequency of misorientation angles smaller than $5^{\circ}$, probably due to the deformation introduced by the machining and subsequent annealing ${ }^{28}$.

The KAM distribution curves, presented in Figure 10, indicate that for the sample in the as-welded condition the peak values are in the smaller KAM than the mechanically polished surface of the annealed after machining sample. The highest peak values for the mechanically polished surface of the annealed after machining sample refer to the greater amount of introduced plastic deformation by the machining stress. Besides that, conventional machining processes cause both an intense plastic deformation and localized heating of the cutting tool contact region ${ }^{29}$, which could implicate in recrystallisation. However, alloys with low stacking fault energy have difficulties to recrystallize during the machining processes, so a displacement of the maximum KAM peak is observed when compared to the as-welded condition. Therefore, the machining process generates higher levels of residual plastic deformation than those generated during deposition of the weld overlay layers.

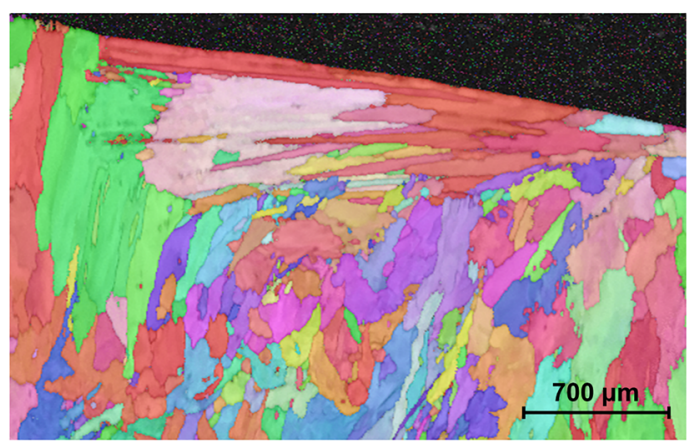

a

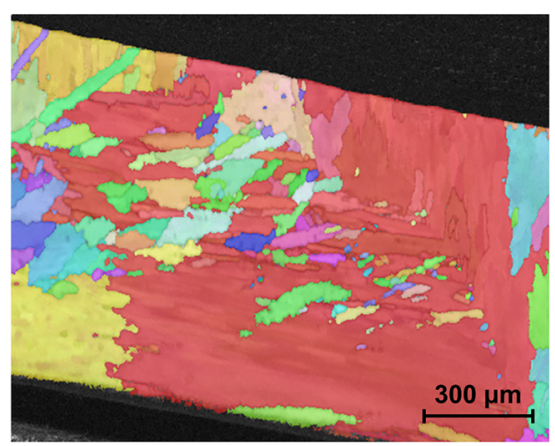

b

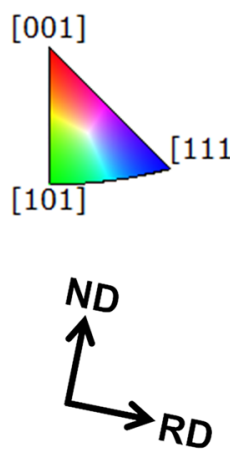

Figure 7. Inverse pole maps in sections of the (a) as-welded clad and (b) machined and annealed clad, both perpendicular to the welding direction (step sizes were $6.56 \mu \mathrm{m}$ and $2.98 \mu \mathrm{m}$, respectively, and the work distances were $17.7 \mathrm{~mm}$ and $19.7 \mathrm{~mm}$, respectively), and EBSD pattern quality. The scanning electron microscope voltage was $20 \mathrm{kV}$. ND and RD indicate normal and radial directions, respectively.

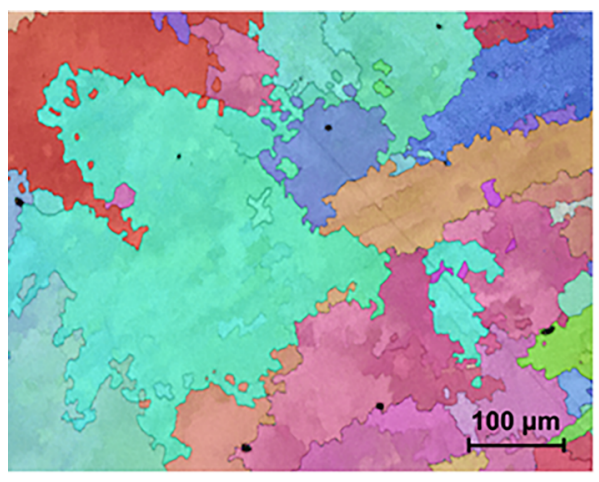

a
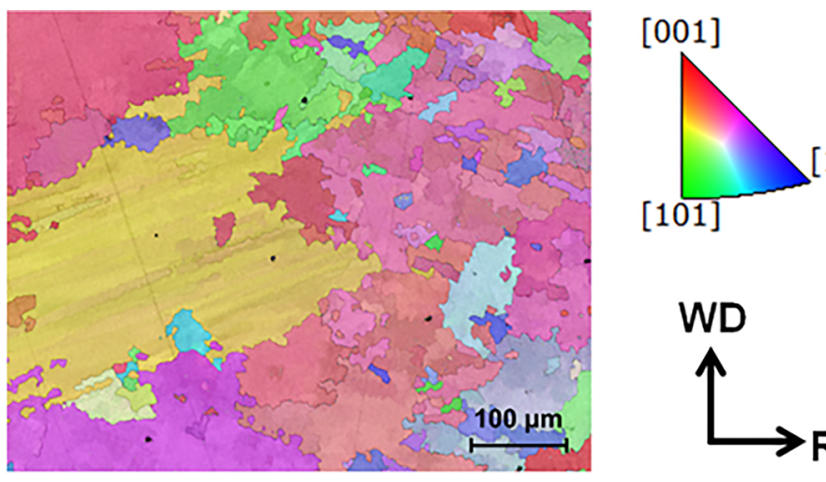

[111]

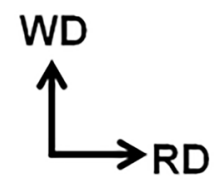

Figure 8. Inverse pole maps in sections of the (a) machined and annealed clad and (b) machined ( $0.15 \mathrm{~mm}$ removal) and annealed once more clad, both parallel to the welding direction (step sizes were $1.19 \mu \mathrm{m}$ and $1.19 \mu \mathrm{m}$, respectively, and the work distances were 18.2 $\mathrm{mm}$ and $15.4 \mathrm{~mm}$, respectively), and EBSD pattern quality. The scanning electron microscope voltage was $20 \mathrm{kV}$. WD and RD indicate welding and radial directions, respectively. 


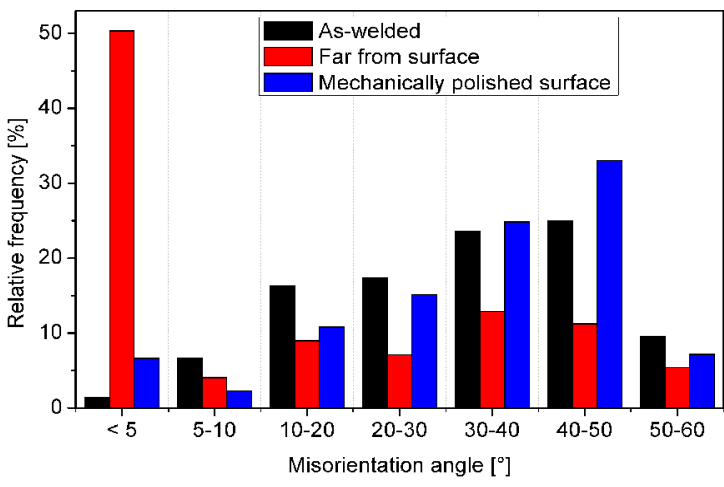

Figure 9. Misorientation angle distributions across as-welded and annealed samples after machining nickel-based alloy 625 clad.

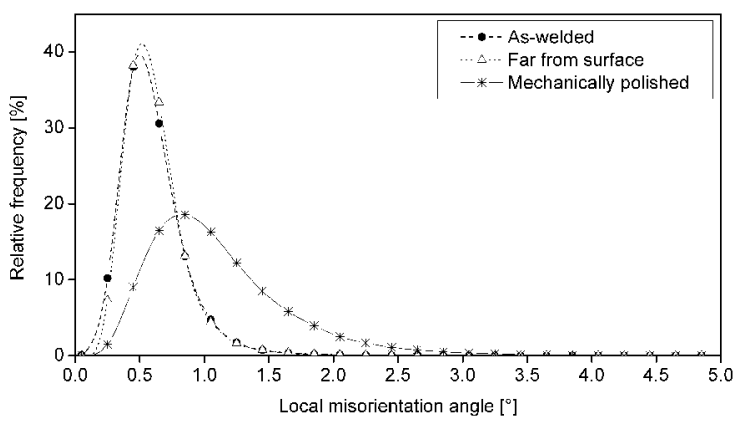

Figure 10. KAM distribution in as-welded and annealed samples after machining Ni-based superalloy 625 clad.

\subsection{Stress-strain relationships}

Table 3 presents data for the elastic region of the stress-strain curve of the nickel-based alloy 625 clad. The average Young's modulus is $207 \pm 2.66 \mathrm{GPa}$.

\subsection{Measurements of X-ray elastic constants}

Figure 5 presented the linear dependence of the diffraction angle with the $\sin ^{2} \psi$ tilts. The interception point and the tangent angle (slope) of the straight line of this dependence for a series of applied stresses (specified in Table 3) were used to determine the X-ray elastic constants. Figure 11 shows the influence of the applied stress on $\left(\theta_{\psi=0}-\theta_{\psi=90}\right)$ and $\left(\theta_{\psi=0^{-}} \theta_{0}\right)$.

The X-ray elastic constants obtained from linear regression of the experimental data presented in Figure 11 are:

$$
\begin{aligned}
\mathrm{S}_{1} & =1.45 \times 10^{-6} \mathrm{MPa}^{-1} \\
\frac{1}{2} \mathrm{~S}_{2} & =6.17 \times 10^{-6} \mathrm{MPa}^{-1}
\end{aligned}
$$

The X-ray Young's modulus and the Poisson's ratio obtained by means of $\mathrm{S}_{1}$ and $\frac{1}{2} \mathrm{~S}_{2}$ are $\mathrm{E}=212 \pm 2 \mathrm{GPa}$ and $v=0.31 \pm 0.01$, respectively.

The principal challenge in elastic constants determination of the nickel-based alloy 625 clad by XRD is associated

Table 3. Experimental data for stress-strain relationships and Young's modulus determination of nickel-based alloy clad

\begin{tabular}{ccccc}
\hline Force $[\mathrm{N}]$ & Deflection $[\mathrm{mm}]$ & Strain $\left[10^{-4} \mathrm{~mm} / \mathrm{mm}\right]$ & Applied stress $[\mathrm{MPa}]$ & Young's modulus [GPa] \\
\hline 2.0 & 0.248 & 3.99 & 83 & 208 \\
2.4 & 0.307 & 4.85 & 102 & 210 \\
2.8 & 0.355 & 5.69 & 118 & 207 \\
3.4 & 0.443 & 6.99 & 144 & 206 \\
3.7 & 0.488 & 7.78 & 158 & 203 \\
4.4 & 0.567 & 8.90 & 187 & 210 \\
\hline
\end{tabular}

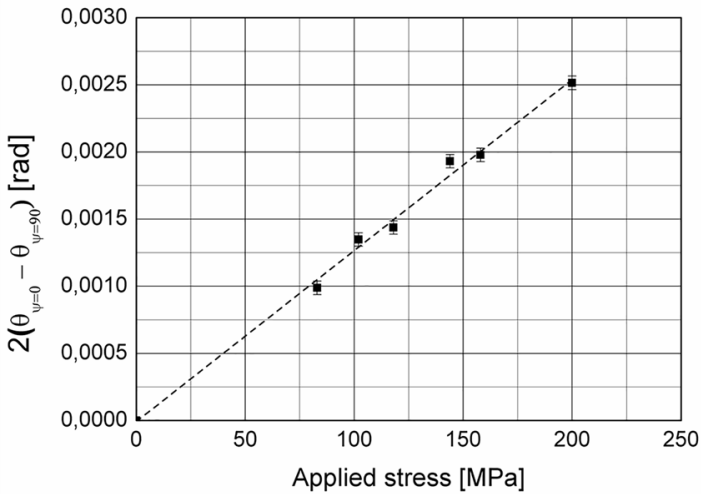

a

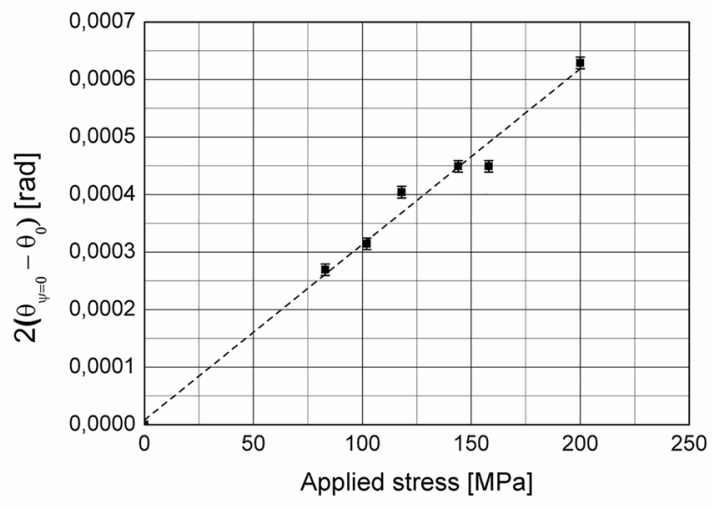

b

Figure 11. Determination of (a) $\left(\theta_{\psi=0}-\theta_{\psi=90}\right)=f\left(\sigma_{P}\right)$ and (b) $\left(\theta_{\psi=0}-\theta_{0}\right)=f\left(\sigma_{P}\right)$ for various applied stresses. 
with the fact that it is coarse-grained and has a preferentially oriented microstructure, which precludes the use of X-ray powder diffraction methods. In this work, it was shown that the as-welded clad does not exhibit the X-ray diffraction pattern in the Bragg-Brentano focusing geometry. The (220) diffraction reflection appears for low $\psi$-tilt angles, i.e., $10^{\circ}$ to $15^{\circ}$, but the accuracy of the peak position determination in this position is not suitable owing to the divergence of the incident X-ray beam and spotty character of the diffraction reflections from the coarse grains. It has been also observed that machining of the clad by grinding and polishing changes the microstructure and submicrostructure of the thin surface layer, which allows the appearance of the diffraction reflections in the Bragg-Brentano and in all other $\psi$-tilt positions. The post machining heat treatment at $1000^{\circ} \mathrm{C}$ eliminates the clad's residual macro and micro stresses, increasing the diffraction line intensity and narrowing its width. However, this high temperature heat treatment does not promote significant alterations in the microstructure of either the machined surface layer or the inner region. This fact was confirmed by Vickers hardness tests on as-welded and annealed (after machining) clads, whose hardness values and curves were similar and exhibited similar shapes (Figure 6).

The EBSD analysis confirmed that the preferred microstructure orientation was not significantly altered during annealing. The GBCD also permitted verification of subgrain formation in the mid thickness of the clad during the heat treatment, which does not occur in the as-welded clad. The KAM distribution in the mid thickness and near to the surface of the annealed clad confirmed the assumption that machining and heat treatment induce different amounts of plastic strain, which was accommodated in each region.

This sample preparation procedure can be useful in the study of some fracture mechanics problems, such as stress concentration and plastic strain around discontinuities (for instance, holes and notches) in coarse grained nickel-based alloys by XRD.

The Young's modulus $(207 \mathrm{GPa})$ determined in this work using the bending loading fixture is close to that obtained by tensile tests ${ }^{30}$ and higher than for pure nickel $(200 \mathrm{GPa})^{31}$. This higher Young's modulus value may be associated with significant content of elements with high elastic properties (e.g., chromium, molybdenum, niobium, and iron). However, the problem of determining the influence of elements on the elastic properties of alloys has not been completely solved ${ }^{32}$. Based on X-ray elastic constants, the X-ray Young's modulus can be determined through the single-crystal stiffness $\mathrm{C}_{\mathrm{ik}}$ and compliance $\mathrm{S}_{\mathrm{mn}}$ tensor components. Using the $\mathrm{C}_{\mathrm{ik}}$ and $\mathrm{S}_{\mathrm{mn}}$ values for pure nickel ${ }^{31}$ and the equations presented in $^{13}$, the X-ray Young's modulus calculated for the (220) crystallographic plane family of pure nickel is $207 \mathrm{GPa}$. Therefore, the ratio between the Young's modulus calculated by X-ray diffraction $\left(\mathrm{E}_{\mathrm{XRD}}\right)$ and mechanical $\left(\mathrm{E}_{\mathrm{MECH}}\right)$ methods characterizes the difference between two Young's moduli, where this ratio is 1.035 for pure nickel.
According to the experimental magnitudes $\left(\mathrm{E}_{\mathrm{MECH}}=207 \mathrm{GPa}\right)$ and $\left(\mathrm{E}_{\mathrm{XRD}}=212 \mathrm{GPa}\right)$ obtained in this work, the $\mathrm{E}_{\mathrm{XRD}} / \mathrm{E}_{\mathrm{MECH}}$ ratio for nickel-based alloy 625 clad is 1.024 . This result supports the reliability of the X-ray elastic constants obtained in this work and allows applying them to XRD stress measurements in nickel-based alloy 625 welds with coarse grains and with an elongated and preferentially oriented microstructure.

\section{Conclusion}

The study of the nickel-based alloy 625 clad on a $9 \%$ Ni steel pipe by X-ray diffraction, electron backscatter diffraction, and Vickers hardness testing yielded the following conclusions:

- The study of a coarse grained and preferentially oriented microstructure by X-ray diffraction can be performed with the proposed sample preparation technique (combination of surface machining by milling and grinding with heat treatment annealing at $1000^{\circ} \mathrm{C}$ ). Annealing reduces microdistortions in the structure, improves the intensity and width of the diffraction lines, and increases the precision and accuracy of the X-ray diffraction experiments, especially for the X-ray elastic constants measurements.

- The modified Cauchy-Lorentzian function increases the accuracy and reliability when fitting the experimental X-ray diffraction data, allows the determination of the diffraction line position, and can be used in refinement techniques.

- The portable bending fixture developed for obtaining $\mathrm{X}$-ray diffraction elastic constants measurements can be applied successfully.

- The region near the machined layer, in contrast to the inner region, which maintains the initial aswelded properties, retains the features of plastically deformed metal.

\section{Acknowledgements}

This work has been conducted with financial support from Shell Brasil Petróleo Ltda. (Shell Brasil), Empresa Brasileira de Pesquisa e Inovação Industrial (Embrapii) and Agência Nacional de Petróleo, Gás Natural e Biocombustíveis (ANP) and was carried out in partnership with Vallourec Soluções Tubulares do Brasil S.A. (Vallourec) and Cladtek do Brasil.

\section{References}

1. Smith LM. Clad steel: An engineering option. In: Proceeding of the $24^{\text {th }}$ Offshore Technology Conference; 1992 May 4-7; Houston, TX, USA. p. 343-355.

2. Lippold JC, Kiser SD, DuPont JN. Welding Metallurgy and Weldability of Nickel-Base Alloys. Hoboken: John Wiley \& Sons; 2011. 
3. Melo RHF, Santos MA, Maciel TM. Avaliação do campo de tensões residuais por difração de raios-X utilizando o método do $\operatorname{sen}^{2} \psi$ em revestimentos metálicos do aço inoxidável E308-L. Soldagem \& Inspeção. 2013;18(1):50-56.

4. Marques MJ, Batista AC, Nobre JP, Loureiro A, Kornmeier JR. A utilização da difração de neutrões na determinação do perfil de tensões residuais em revestimentos por soldadura. Soldagem \& Inspeção. 2013;18(2):149-157.

5. Francis JA, Bhadeshia HKDH, Withers PJ. Welding residual stresses in ferritic power plant steels. Materials Science and Technology. 2007;23(9):1009-1020.

6. Ghanem F, Sidhom H, Braham C, Fitzpatrick ME. Effect of near-surface residual stress and microstructure modification from machining on the fatigue endurance of a tool steel. Journal of Materials Engineering and Performance. 2002;11(6):631-639.

7. Anastassiou M, Babbit M, Lebrun JL. Residual stresses and microstructure distribution in spot-welded steel sheets: Relation with fatigue behavior. Materials Science and Engineering: $A$. 1990;125(2):141-156.

8. van Boven G, Chen W, Rogge R. The role of residual stress in neutral $\mathrm{pH}$ stress corrosion cracking of pipeline steels. Part I: Pitting and cracking occurrence. Acta Materialia. 2007;55(1):29-42.

9. Bai L, Jiang K, Gao L. The Influence and Mechanism of Residual Stress on the Corrosion Behavior of Welded Structures. Materials Research. 2018;21(5):e20180166.

10. Luo Q, Jones AH. High-precision determination of residual stress of polycrystalline coatings using optimized XRD- $\sin ^{2} \psi$ technique. Surface \& Coatings Technology. 2010;205(5):14031408 .

11. Hauk VM. X-ray methods for measuring residual stress. In: Proceedings of the $28^{\text {th }}$ Sagamore Army Materials Research Conference; 1982 July 13-17; Boston, MA, USA. p. 117138.

12. Taylor A. X-ray Metallography. New York: Wiley; 1961.

13. Noyan IC, Cohen JB. Residual Stress: Measurement by Diffraction and Interpretation. New York: Springer; 1987.

14. ASTM International. ASTM A333/A333M-11 - Standard Specification for Seamless and Welded Steel Pipe for LowTemperature Service. West Conshohocken: ASTM International; 2011.

15. American Welding Society (AWS). AWS A5.14/A5.14M Specification for nickel and nickel-alloy bare welding electrodes and rods. Miami: AWS; 2005.

16. Hielscher R, Schaeben H. A novel pole figure inversion method: specification of the MTEX algorithm. Journal of Applied Crystallography. 2008;41:1024-1037.
17. Liu Q, Jensen DJ, Hansen N. Effect of grain-orientation on deformation structure in cold-rolled polycrystalline aluminium. Acta Materialia. 1998;46(16):5819- 5838.

18. Hull D, Bacon DJ. Introduction to Dislocations. Oxford: Butterworth-Heinemann; 2001.

19. ASTM International. ASTM E384-17 - Standard Test Method for Microindentation Hardness of Materials. West Conshohocken: ASTM International; 2017.

20. ASTM International. ASTM E92-17 - Standard Test Methods for Vickers Hardness and Knoop Hardness of Metallic Materials. West Conshohocken: ASTM International; 2017.

21. British Standard Institution (BSI). BSEN 15305 - Non-destructive Testing - Test Method for Residual Stress Analysis by X-ray Diffraction. London: BSI; 2008.

22. Farias FWC, Payão Filho JC, Azevedo LMB. Microstructural and Mechanical Characterization of the Transition Zone of $9 \% \mathrm{Ni}$ Steel Cladded with Ni-Based Superalloy 625 by GTAW-HW. Metals. 2018;8:1007.

23. Silva CC, Albuquerque VHC, Miná EM, Moura EP, Tavares JMRS. Mechanical Properties and Microstructural Characterization of Aged Nickel-based Alloy 625 Weld Metal. Metallurgical and Materials Transactions A. 2018;49(5):1653-1673.

24. Cortial F, Corrieu JM, Vernot-Loier C. Influence of heat treatments on microstructure, mechanical properties, and corrosion resistance of weld alloy 625. Metallurgical and Materials Transactions A. 1995;26(5):1273-1286.

25. Voort GFV. Microidentation hardness testing. In: Kuhn H, Medlin D, eds. ASM Handbook Volume 8: Mechanical and Testing Evaluation. Materials Park: ASM International; 2010. p. 469-495.

26. Kim JS, Lee HW. Effect of Welding Heat Input on Microstructure and Texture of Inconel 625 Weld Overlay Studied Using the Electron Backscatter Diffraction Method. Metallurgical and Materials Transactions A. 2016;47(12):6109-6120.

27. Cahn RW, Haasen P, eds. Physical Metallurgy. Amsterdam: North Holland; 1996.

28. Moussa C, Bernacki M, Besnard R, Bozzolo N. About quantitative EBSD analysis of deformation and recovery substructures in pure Tantalum. IOP Conference Series: Materials Science and Engineering. 2015;89:012038.

29. Vaz M Jr. On the Numerical Simulation of Machining Processes. Journal of the Brazilian Society of Mechanical Sciences. 2000;22(2):179-188.

30. Special Metals. Inconel ${ }^{\circledR}$ alloy 625. 2013. www.specialmetals.com.

31. Huntington HB. The Elastic Constants of Crystals. Solid State Physics. 1958;7:213-351.

32. Wang YJ, Wang CY. Influence of alloying elements on the elastic properties of ternary and quaternary nickel base superalloys. Philosophical Magazine. 2009;89(32):2935-2947. 